\title{
Gastrointestinal endoscopy capacity in Eastern Africa
}

\section{다 (우우}

Authors

Michael Mwachiro*, 1 , Hillary M. Topazian ${ }^{*, 2}$, Violet Kayamba ${ }^{3}$, Gift Mulima ${ }^{4}$, Elly Ogutu, ${ }^{5,6}$, Mengistu Erkie, Gome Lenga $^{8}$, Thomas Mutie ${ }^{6,9}$, Eva Mukhwana ${ }^{6}$, Hailemichael Desalegn ${ }^{10}$, Rezene Berhe ${ }^{11}$, Berhane Redae Meshesha ${ }^{12}$, Bongani Kaimila ${ }^{13}$, Paul Kelly ${ }^{3}$, David Fleischer ${ }^{14}$, Sanford M. Dawsey ${ }^{15}$, Mark D. Topazian ${ }^{16}$

Institutions

1 Department of Endoscopy and Surgery, Tenwek Hospital, Bomet, Kenya

2 Department of Epidemiology, University of North Carolina at Chapel Hill, Chapel Hill, North Carolina, United States

3 University of Zambia School of Medicine, Lusaka, Zambia

4 Kamuzu Central Hospital, Lilongwe Malawi

5 Department of Clinical Medicine \& Therapeutics, University of Nairobi, Kenya

6 World Gastroenterology Organization Training Centre, Nairobi, Kenya

7 Division of Gastroenterology \& Hepatology, Department of Internal Medicine, Addis Ababa University, College of Health Sciences, Ethiopia

8 Department of Medical Services, Kenya Ports Authority

9 Department of Gastroenterology, Nairobi Hospital

10 Division of Gastroenterology and Hepatology, St. Paul's Hospital Millennium Medical College, Addis Ababa, Ethiopia

11 Division of Gastroenterology \& Hepatology, Department of Internal Medicine, Addis Ababa University, College of Health Sciences, Ethiopia

12 Department of Surgery, Saint Paul's Hospital Millennium Medical College, Addis Ababa, Ethiopia

13 UNC Project, Lilongwe Malawi University

14 Division of Gastroenterology and Hepatology, Mayo Clinic, Phoenix, Arizona

15 Division of Cancer Epidemiology and Genetics, National Cancer Institute, National Institutes of Health, Bethesda, Maryland, United States

16 Division of Gastroenterology and Hepatology, Mayo Clinic, Rochester, Minnesota, United States

submitted 6.5.2021

accepted after revision 9.7.2021

Bibliography

Endosc Int Open 2021; 09: E1827-E1836

DOI 10.1055/a-1551-3343

ISSN 2364-3722

\section{(C) 2021. The Author(s).}

This is an open access article published by Thieme under the terms of the Creative Commons Attribution-NonDerivative-NonCommercial License, permitting copying and reproduction so long as the original work is given appropriate credit. Contents may not be used for commercial purposes, or adapted, remixed, transformed or built upon. (https://creativecommons.org/licenses/by-nc-nd/4.0/)

Georg Thieme Verlag KG, Rüdigerstraße 14,

70469 Stuttgart, Germany

Corresponding author

Michael Mwachiro, P.O. Box 39-20400, Tenwek Hospital,

Bomet, Kenya

deche2002@yahoo.com

$\bigoplus$ Supplementary material is available under
https://doi.org/10.1055/a-1551-3343

\section{ABSTRACT}

Background and study aims Limited evidence suggests that endoscopy capacity in sub-Saharan Africa is insufficient to meet the levels of gastrointestinal disease. We aimed to quantify the human and material resources for endoscopy services in eastern African countries, and to identify barriers to expanding endoscopy capacity.

Patients and methods In partnership with national professional societies, digestive healthcare professionals in participating countries were invited to complete an online survey between August 2018 and August 2020.

Results Of 344 digestive healthcare professionals in Ethiopia, Kenya, Malawi, and Zambia, 87 (25.3\%) completed the survey, reporting data for 91 healthcare facilities and identifying 20 additional facilities. Most respondents (73.6\%) perform endoscopy and $59.8 \%$ perform at least one therapeutic modality. Facilities have a median of two functioning gastroscopes and one functioning colonoscope each. Overall endoscopy capacity, adjusted for non-response and additional facilities, includes 0.12 endoscopists, 0.12 gastroscopes, and 0.09 colonoscopes per 100,000 population in the participating countries. Adjusted maximum upper gastrointestinal and lower gastrointestinal endoscopic capaci-

\footnotetext{
* These authors contributed equally.
} 
ty were 106 and 45 procedures per 100,000 persons per year, respectively. These values are $1 \%$ to $10 \%$ of those reported from resource-rich countries. Most respondents identified a lack of endoscopic equipment, lack of trained endoscopists and costs as barriers to provision of endoscopy services.
Conclusions Endoscopy capacity is severely limited in eastern sub-Saharan Africa, despite a high burden of gastrointestinal disease. Expanding capacity requires investment in additional human and material resources, and technological innovations that improve the cost and sustainability of endoscopic services.

\section{Introduction}

Gastrointestinal endoscopy is an essential diagnostic and therapeutic tool of modern medicine. Anecdotal evidence suggests that there is insufficient endoscopy capacity in low- and middle-income countries (LMICS), but there are few published quantitative data to support this conclusion. A prior survey of endoscopists in sub-Saharan Africa highlighted the lack of therapeutic and emergency endoscopy services, the paucity of endoscopy training centers in the region, and the need for more endoscopy training [1].

The African Esophageal Cancer Consortium (AfrECC), formed in 2017, is a multinational consortium of healthcare professionals, researchers, and public health specialists seeking to prevent endemic esophageal squamous cell cancer (ESCC), improve esophageal cancer care and stimulate esophageal cancer (EC) research [2]. ESCC is highly prevalent in eastern sub-Saharan Africa, in a corridor stretching from Ethiopia to South Africa, and AfrECC's efforts are focused in this area of the globe. Gastrointestinal endoscopy is a pivotal technology for EC care, research, and prevention.

Diseases requiring endoscopy (including esophageal and gastric cancers, peptic ulcers, and variceal hemorrhage) are more common in LMICs than in resource-rich countries and thus there is a need to assess if endoscopic services are sufficient for current needs [3]. In the recent past there have been several publications highlighting the sub-Saharan gastrointestinal endoscopy experience and suggesting that endoscopy is an appropriate technology for the region [4-7].

AfrECC undertook a survey of digestive healthcare professionals with the goal of quantitatively assessing endoscopy capacity in eastern Africa. AfrECC is ideally positioned to sponsor such a survey, and AfrECC members in Ethiopia, Kenya, Malawi and Zambia agreed to serve as champions for the project in their respective countries. Efforts were made to survey all healthcare professionals potentially performing endoscopy by working in collaboration with national gastroenterology and surgery societies.

The aims of this study were to determine the number of $\mathrm{Gl}$ endoscopists practicing in participating eastern African countries, the scope of their practice, and their practice settings. Both human resources and material resources available for endoscopy were evaluated, with the aim of estimating endoscopy capacity (in terms of both manpower and equipment) in participating countries, comparing these results to published data from resource-rich countries, and identifying barriers to expanded endoscopy capacity in the region.

\section{Material and methods}

Invitations to participate in a standardized online survey were sent to all known and potential gastrointestinal endoscopists in Ethiopia, Kenya, Malawi and Zambia, and anonymized results were analyzed and compared to published data from South Africa, North America, and Europe. Invitations were issued in partnership with professional societies of participating countries: in Country A the survey was sent to members of the national gastroenterology society (including surgeons who are members), while in Country B, Country C, and Country D, the survey was sent to members of both gastroenterology and surgery societies. Invitations were distributed to the entire memberships of these societies via email and WhatsApp forum. Periodic reminders were sent to all invitees. The survey included items about the respondent's scope of practice, the endoscopy equipment available at the facilities where they perform endoscopy, and the maximum number of endoscopic procedures that could be performed weekly at those facilities. Health facilities were classified by level of care provision. Primary facilities serve populations at the county or district level, secondary are regional facilities, and tertiary are national referral hospitals. Participants were also asked to list other healthcare facilities in their country where endoscopy might be performed. The survey instrument is shown in Supplemental Table 1.

Data were collected through Google Forms and stored and analyzed at the University of North Carolina (UNC) at Chapel Hill. Data regarding scope of endoscopic practice was analyzed with regard to the percentage of respondents who are practicing particular therapeutic interventions and their self-reported desire for further training in particular endoscopic interventions. Descriptive statistics were used to report both endoscopist and equipment data, and summary data for each country were compared to the country population to obtain a measure of endoscopic capacity in terms of both endoscopists and functioning endoscopes available per unit of population. The maximum number of endoscopic procedures that could be performed across all survey responses was similarly analyzed, based on respondents estimates of the maximum number of procedures facilities could perform per week. When more than one respondent reported data about a healthcare facility, which occurred for many larger facilities, we used facility mean values for data analysis.

For analyses of nation-wide endoscopy capacity, summary results were adjusted to account for survey non-responders. "Capacity" was calculated using data from all survey respondents, and "adjusted capacity" was calculated by extrapolating 
results to all individuals invited to participate in the survey, including all nonrespondents. Facility-level data was similarly adjusted to include all facilities reportedly offering endoscopy services, including those for which data were not available. These calculations were based on the assumption that the endoscopy practice of nonrespondents is, on average, the same as that of survey respondents. All tabulations were performed using $\mathrm{R}$ 3.6.2 (R Foundation for Statistical Computing, Vienna, Austria).

Endoscopist and procedure volume data were compared to previously published data from South Africa, the United States, and the Netherlands. Because data were not available regarding the number of functioning gastroscopes and colonoscopes in use in the United States and the Netherlands, we estimated lower limits from the known number of procedures done yearly in these countries, assuming that each endoscope could be used to perform a maximum of 1,000 procedures yearly.

\section{Results}

Invitations were sent to 344 individuals, and 87 (25.3\%) completed the survey. Details of the respondents' endoscopy practices are shown in $>$ Table $\mathbf{1}$, and their practice locations are depicted in > Fig. 1. Among all participants, $73.6 \%$ perform endoscopic procedures and $59.8 \%$ perform at least one endoscopic therapeutic modality; six perform ERCP and two perform EUS. Fifteen of the respondents (4.4\%) are either members of AfrECC or have attended an AfrECC esophageal stent training workshop. Only $6.9 \%$ of respondents reported wanting more training in diagnostic endoscopy, while $67.8 \%$ reported wanting additional training in therapeutic endoscopy, including ERCP (52.9\%), endoscopic submucosal dissection (50.6\%), endoscopic ultrasound (49.4\%), endoscopic mucosal resection (47.1\%), non-variceal bleeding therapies (46.0\%), pneumatic dilation for achalasia (34.5\%), esophageal stent placement (32.2\%), polypectomy (28.7\%), esophageal dilation (24.1\%), and variceal band ligation (21.8\%).

The respondents perform endoscopy at 91 medical facilities and knew of an additional 20 facilities where endoscopy is reportedly available, but for which no survey data was obtained. - Table 2 compares endoscopy practice characteristics at the 91 facilities, sub-categorized as public, private, or mission facilities. The majority of endoscopists at all facility types practice at secondary and tertiary level institutions. Overall, these facilities have a median of one functioning colonoscope (IQR: 1-2) and two gastroscopes (IQR: 1-3) each. Fluoroscopy is more commonly available at mission facilities than at public or private endoscopy practices, and endoscopy fees are much lower at public institutions. Fewer than half of facilities offer afterhours or weekend emergency endoscopy services.

The overall endoscopic capacity of participating countries is shown in > Table $3[8,9]$, including both the number of endoscopists and maximum procedure capacity of facilities offering endoscopy services. Endoscopy capacity of each individual country is shown in Supplemental Table 2. "Adjusted capacity" (as defined in the methods section) was compared to published endoscopy utilization data from the West Cape Province in South Africa, the United States, and the Netherlands. Per unit population, the adjusted number of endoscopists in participating countries was only $10.0 \%$ and $4.8 \%$ of the number of endoscopists in the United States and Netherlands, respectively. Similarly, the number of functioning gastroscopes in participating countries was $6.8 \%$ and $9.4 \%$, the number of available colonoscopes was $2.6 \%$ and $5.7 \%$, the maximum upper gastrointestinal endoscopy capacity was $5.8 \%$ and $8.1 \%$, and the maximum lower gastrointestinal endoscopy capacity was $1.4 \%$ and $3.0 \%$ of capacity in the United States and the Netherlands, respectively. Comparison of adjusted country-level results to values from the West Cape Province resulted in $13.5 \%, 20.9 \%, 33.2 \%$, $63.6 \%$ of the capacity for functioning gastroscopes, functioning colonoscopes, maximum upper gastrointestinal capacity, and maximum lower gastrointestinal capacity, respectively.

Perceived barriers preventing or limiting endoscopy services are shown in $\nabla$ Table $\mathbf{4}$ and Supplemental Table 3 . At the facility level, public sector facilities more often lacked equipment (75\%) compared to the private sector (50\%). Fewer individuals working in the public sector reported time constraints as a barrier and more reported purchase of endoscopy equipment as a barrier. Overall, $75.9 \%$ of respondents reported a lack of endoscopy equipment, $83.3 \%$ reported cost-related barriers, $69.0 \%$ reported lack of trained endoscopists and/or support staff, $40.5 \%$ reported facility infrastructure and resource constraints, and $38.1 \%$ reported regulatory and governmental barriers to endoscopy services.

- Table 5 presents data about how facilities obtain and repair endoscopes. Endoscope procurement varies by country, but facility-level purchases are common, and donations are an important source of endoscopes. Nearly half (47.9\%) of respondents must send their endoscopes to another continent for repair, and a quarter either have no access to repair (21.9) or else attempt self-repair (13.7\%). Many respondents must look outside of their facility for funds to pay for endoscope repair; when funds are available, they usually come from research grants (18.2\%), the government $(9.1 \%)$, a donor $(12.1 \%)$, or the endoscopist themselves (13.6\%).

\section{Discussion}

Anecdotal evidence has long suggested critical shortages of both trained gastrointestinal endoscopists and endoscopic equipment in sub-Saharan Africa, but there is little published data to substantiate this impression. In this study, nationwide surveys conducted in the four countries demonstrated severely limited gastrointestinal endoscopy capacity when compared to South Africa, the United States, and the Netherlands [10]. Human resources (endoscopists and trained assistants) and material resources (endoscopes) in participating countries equate to $\leq 10 \%$ of the resources found in high income countries.

Our findings add to those of previous investigators who collected survey data from 22 endoscopists practicing in 15 different sub-Saharan countries, often with only one respondent per country [1]. The authors highlighted the limited scope of reported endoscopy services and the need for additional training, particularly in therapeutic endoscopy. Similarly, a survey of West African healthcare professionals attending a 3-day course 
- Table 1 Demographic characteristics of survey respondents.

\begin{tabular}{|c|c|c|c|c|c|c|c|c|c|c|}
\hline & \multicolumn{2}{|c|}{ Country A } & \multicolumn{2}{|c|}{ Country B } & \multicolumn{2}{|c|}{ Country C } & \multicolumn{2}{|c|}{ Country D } & \multicolumn{2}{|c|}{ Total } \\
\hline Survey start date & \multicolumn{2}{|c|}{ 24-Dec-2019 } & \multicolumn{2}{|c|}{ 7-Aug-2019 } & \multicolumn{2}{|c|}{ 17-Aug-2018 } & \multicolumn{2}{|c|}{ 19-Jul-2019 } & \multicolumn{2}{|c|}{ 17-Aug-2018 } \\
\hline Survey end date & \multicolumn{2}{|c|}{ 10-May-2020 } & \multicolumn{2}{|c|}{ 12-Aug-2020 } & \multicolumn{2}{|c|}{ 11-Aug-2020 } & \multicolumn{2}{|c|}{ 1-Nov-2019 } & \multicolumn{2}{|c|}{ 12-Aug-2020 } \\
\hline Number invited to participate (row \%) & \multicolumn{2}{|c|}{$66(19.2)$} & \multicolumn{2}{|c|}{$201(58.4)$} & \multicolumn{2}{|c|}{$10(2.9)$} & \multicolumn{2}{|c|}{$67(19.5)$} & \multicolumn{2}{|c|}{$344(100.0)$} \\
\hline Number of respondents (row \%) & \multicolumn{2}{|c|}{$15(17.2)$} & \multicolumn{2}{|c|}{$49(56.3)$} & \multicolumn{2}{|c|}{$7(8.0)$} & \multicolumn{2}{|c|}{$16(18.4)$} & \multicolumn{2}{|c|}{$87(100.0)$} \\
\hline \multirow[t]{2}{*}{ Response rate (\%) } & \multicolumn{2}{|c|}{22.7} & 24. & & 70 & & 23 & & 25. & \\
\hline & $\mathbf{n}$ & $\%$ & $\mathbf{n}$ & $\%$ & $\mathbf{n}$ & $\%$ & $\mathbf{n}$ & $\%$ & $\mathbf{n}$ & $\%$ \\
\hline Type of health professional & & & & & & & & & & \\
\hline - Surgeon & 2 & 13.3 & 34 & 69.4 & 4 & 57.1 & 2 & 12.5 & 42 & 48.3 \\
\hline - MD non-surgeon & 13 & 86.7 & 5 & 10.2 & 1 & 14.3 & 8 & 50.0 & 27 & 31.0 \\
\hline - Non-physician & 0 & 0.0 & 3 & 6.1 & 2 & 28.6 & 4 & 25.0 & 9 & 10.3 \\
\hline - Trainee/fellow & 0 & 0.0 & 7 & 14.3 & 0 & 0.0 & 2 & 12.5 & 9 & 10.3 \\
\hline Place of employment & & & & & & & & & & \\
\hline - Private sector & 3 & 20.0 & 17 & 34.7 & 1 & 14.3 & 1 & 6.3 & 22 & 25.3 \\
\hline - Public sector & 4 & 26.7 & 19 & 38.8 & 2 & 28.6 & 15 & 93.8 & 40 & 46.0 \\
\hline - Both & 8 & 53.3 & 13 & 26.5 & 0 & 0.0 & 0 & 0.0 & 21 & 24.1 \\
\hline Performing gastrointestinal endoscop & roce & & & & & & & & & \\
\hline - No & 2 & 13.3 & 16 & 32.7 & 0 & 0 & 4 & 25 & 22 & 25.3 \\
\hline - Yes & 13 & 86.7 & 33 & 67.3 & 7 & 100 & 11 & 68.8 & 64 & 73.6 \\
\hline Procedures performed & & & & & & & & & & \\
\hline - Diagnostic EGD & 13 & 86.7 & 33 & 67.3 & 3 & 42.9 & 12 & 75.0 & 61 & 70.1 \\
\hline - Diagnostic colonoscopy & 13 & 86.7 & 28 & 57.1 & 2 & 28.6 & 8 & 50.0 & 51 & 58.6 \\
\hline - Diagnostic ERCP & 1 & 6.7 & 4 & 8.2 & 0 & 0.0 & 1 & 6.3 & 6 & 6.9 \\
\hline - EUS & 0 & 0.0 & 1 & 2.0 & 0 & 0.0 & 1 & 6.3 & 2 & 2.3 \\
\hline - Any therapeutic endoscopy & 13 & 86.7 & 27 & 55.1 & 1 & 14.3 & 11 & 68.8 & 52 & 59.8 \\
\hline Injection therapy for bleeding & 9 & 60.0 & 17 & 34.7 & 0 & 0.0 & 8 & 50.0 & 34 & 39.1 \\
\hline Variceal band ligation & 11 & 73.3 & 23 & 46.9 & 1 & 14.3 & 11 & 68.8 & 46 & 52.9 \\
\hline Endoscopic clip placement & 5 & 33.3 & 7 & 14.3 & 0 & 0.0 & 5 & 31.3 & 17 & 19.5 \\
\hline Esophageal dilation & 6 & 40.0 & 24 & 49.0 & 1 & 14.3 & 9 & 56.3 & 40 & 46.0 \\
\hline Esophageal stent placement & 0 & 0.0 & 22 & 44.9 & 1 & 14.3 & 6 & 37.5 & 29 & 33.3 \\
\hline Polypectomy & 11 & 73.3 & 14 & 28.6 & 0 & 0.0 & 7 & 43.8 & 32 & 36.8 \\
\hline EMR & 2 & 13.3 & 3 & 6.1 & 0 & 0.0 & 0 & 0.0 & 5 & 5.7 \\
\hline ESD & 1 & 6.7 & 1 & 2.0 & 0 & 0.0 & 0 & 0.0 & 2 & 2.3 \\
\hline
\end{tabular}

on the diagnosis and treatment of gastrointestinal disease found that fewer than half of attendees had the resources needed to perform endoscopy [11]. Our study adds to previous work by quantifying national endoscopy capacity, drawing comparisons with resource-rich countries, and further exploring barriers to expansion of endoscopy services.

A case might be made that fewer endoscopy resources are required in sub-Saharan Africa than in Europe or North America, arguing that colonoscopic population screening is not need- ed due to the relatively low incidence of colorectal cancer in the region, and that upper gastrointestinal endoscopy may be overused in resource-rich countries for evaluation of conditions such as dyspepsia. However, ESCC is up to 50 times more common in eastern Africa than in Europe and North America [2], and endoscopy is pivotal in the diagnosis, management and prevention of this disease. ESCC screening programs are needed in the region, but population-wide screening and endoscopic treatment of esophageal squamous dysplasia (the ESCC 
$>$ Table 1 (Continuation)

\begin{tabular}{|c|c|c|c|c|c|c|c|c|c|c|}
\hline & \multicolumn{2}{|c|}{ Country A } & \multicolumn{2}{|c|}{ Country B } & \multicolumn{2}{|c|}{ Country C } & \multicolumn{2}{|c|}{ Country D } & \multicolumn{2}{|l|}{ Total } \\
\hline & median & IQR & median & IQR & median & $I Q R$ & median & $I Q R$ & median & IQR \\
\hline Number of years performing endoscopy & 6 & $5-6$ & 5 & $3-8$ & 5 & $3.5-8$ & 7 & $\begin{array}{l}3.75- \\
15.25\end{array}$ & 5 & $3-9$ \\
\hline $\begin{array}{l}\text { Average number of upper gastrointes- } \\
\text { tinal endoscopies/week }\end{array}$ & 20 & $20-30$ & 6 & $3.5-12.5$ & 10 & $\begin{array}{l}8.5- \\
13.75\end{array}$ & 8 & $5-11$ & 10 & $4.5-15.5$ \\
\hline $\begin{array}{l}\text { Average number of lower gastrointesti- } \\
\text { nal endoscopies/week }\end{array}$ & 8 & $5-10$ & 2 & $1-4$ & 1 & $0.5-2$ & 0 & $0-3.5$ & 3 & $1-5$ \\
\hline
\end{tabular}

EGD, esophagogastroduodenoscopy; ERCP, endoscopic retrograde cholangiopancreatography; EUS, endoscopic ultrasound; EMR, endoscopic mucosal resection; ESD, endoscopic submucosal dissection.

Missing values for country a, b, $c$, d: type of health professional $(0,0,0,0)$; place of employment $(0,0,4,0)$; performing gastroenterology $(0,0,0,1)$; procedures performed $(2,16,4,4)$; years performing endoscopy $(2,16,0,4)$; number of upper gastrointestinal endoscopies $(2,16,1,5)$; number of lower gi endoscopies $(2,16,0,5)$.

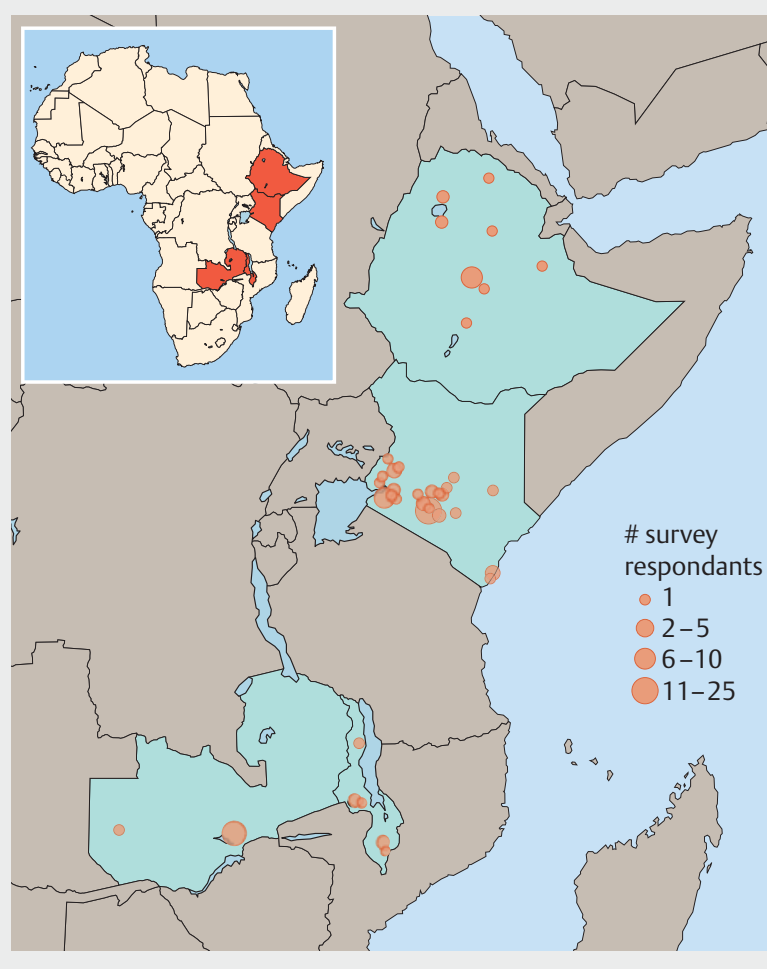

- Fig. 1 Health facility locations reported by survey participants $(n=91)$, stratified by country and facility type.

precursor) is not currently feasible given the lack of endoscopic resources. In addition, a wide variety of other gastrointestinal diseases, including viral hepatitis-induced cirrhosis, hepatocellular cancer, schistosomiasis, variceal hemorrhage, peptic ulcer disease, gastric cancer and gastrointestinal tuberculosis are more prevalent in sub-Saharan Africa than in Europe or North America [12-15]. The burden of gastrointestinal disease in sub-Saharan Africa calls for endoscopy resources at least as robust as those found in resource-rich countries.

Even after adjusting our results to account for non-responders, we found that there is only one endoscopist for every
400,000 to 2 million individuals in participating countries. As a consequence of this severe shortage, we have observed that many sub-Saharan endoscopists spend much of their effort on diagnosis and management of life-threatening complications of advanced disease. Endoscopic services intended to screen for, prevent, or modify disease often take a back seat to urgent evaluation of severely symptomatic patients. The overall impact of endoscopy on the health of African populations would likely be greater if there were enough endoscopists to fully support elective and preventative endoscopy services as well. We are encouraged that the median endoscopist in this survey has been practicing for only 6 years, suggesting that human resources for endoscopy have been increasing in recent years.

Similarly, we found that there is only one functioning gastroscope for every 400,000 to 1.3 million individuals in participating countries, less than $10 \%$ of the minimum number of gastroscopes that we calculated are needed to support current endoscopy practice volumes in the United States and the Netherlands. Quantitative endoscopy capacity data has also been published for West Cape Province, South Africa, based on an audit of facilities offering endoscopy, and reported 0.90 functioning gastroscopes and 0.41 functioning colonoscopes per 100,000 population; similar data has been reported from KwaZula-Natal Province $[8,16,17]$. These figures are midway between those of the eastern African countries we surveyed and the Netherlands and United States, and suggest that there is probably a range of endoscopy capacity across LMICs. We found that private facilities and faith-based institutions hold the majority of endoscopy resources within countries. This may be a function of the cost of acquiring and maintaining the equipment. In addition, the equipment numbers provided are also reported averages and may not have captured the variability in periods when there was limited or no functional equipment at all. Endoscopy fees are lower at public facilities, but there were few public facilities that offered endoscopy services, suggesting very limited access for poorer patients.

A large majority of survey respondents identified the initial cost of endoscopic equipment and the ongoing costs of maintaining equipment as barriers to the provision of endoscopy services. Further complicating matters, most respondents do 
- Table 2 Endoscopy services and resources by type of healthcare institution.

\begin{tabular}{|c|c|c|c|c|c|c|c|c|c|}
\hline & \multicolumn{2}{|c|}{ All facilities } & \multicolumn{2}{|l|}{ Mission } & \multicolumn{2}{|l|}{ Private } & \multicolumn{2}{|l|}{ Public } & \multirow[t]{2}{*}{$P$ value $^{1}$} \\
\hline & n & $\%$ & $\mathbf{n}$ & $\%$ & $\mathbf{n}$ & $\%$ & n & $\%$ & \\
\hline \# facilities represented & 91 & - & 9 & - & 65 & - & 17 & - & \\
\hline \multicolumn{10}{|l|}{ Facility level of service ${ }^{2}$} \\
\hline - Outpatient clinic & 2 & 2.2 & 0 & 0.0 & 2 & 3.1 & 0 & 0.0 & $1.0^{3}$ \\
\hline - Primary & 3 & 3.3 & 0 & 0.0 & 2 & 3.1 & 1 & 5.9 & \\
\hline - Secondary & 34 & 37.4 & 6 & 66.7 & 28 & 43.1 & 0 & 0.0 & \\
\hline - Tertiary & 32 & 35.2 & 3 & 33.3 & 13 & 20.0 & 16 & 94.1 & \\
\hline \multicolumn{10}{|l|}{ Days per week that endoscopy is available } \\
\hline . 1 & 7 & 7.7 & 1 & $11 . .1$ & 4 & $6 . .2$ & 2 & 11.8 & $0.9^{4}$ \\
\hline . $2-4$ & 18 & 19.8 & 2 & 22.2 & 11 & 16.9 & 5 & 29.4 & \\
\hline .5 & 19 & 20.9 & 5 & 55.6 & 9 & 13.8 & 5 & 29.4 & \\
\hline . $6-7$ & 25 & 27.5 & 0 & 0.0 & 20 & 30.8 & 5 & 29.4 & \\
\hline \multicolumn{10}{|l|}{ Emergency endoscopy } \\
\hline - No & 16 & 17.6 & 2 & 22.2 & 9 & 13.8 & 5 & 29.4 & $0.8^{* *}$ \\
\hline - Yes & 3 & 3.3 & 1 & 11.1 & 1 & 1.5 & 1 & 5.9 & \\
\hline - Yes, but during scheduled hours only & 28 & 30.8 & 2 & 22.2 & 22 & 33.8 & 4 & 23.5 & \\
\hline $\begin{array}{l}\text { - Yes, during scheduled hours and after } \\
\text { hours }\end{array}$ & 24 & 26.4 & 4 & 44.4 & 13 & 20.0 & 7 & 41.2 & \\
\hline \multicolumn{10}{|l|}{ Access to fluoroscopy } \\
\hline - No & 49 & 53.8 & 2 & 22.2 & 36 & 55.4 & 11 & 64.7 & 0.003 \\
\hline \multirow[t]{2}{*}{ - Yes } & 22 & 24.2 & 7 & 77.8 & 9 & 13.8 & 6 & 35.3 & \\
\hline & Median & IQR & Median & IQR & Median & IQR & Median & IQR & \\
\hline Functioning gastroscopes per facility & 2 & $1-3$ & 3 & $2-4$ & 1 & $1-2$ & 2 & $1.89-3.5$ & 0.002 \\
\hline Functioning colonoscopes per facility & 1 & $1-2$ & 1 & $1-2$ & 1 & $1-2$ & 1 & $1-2$ & 0.8 \\
\hline $\begin{array}{l}\text { Maximum capacity for upper gastrointes- } \\
\text { tinal procedures per week per facility }\end{array}$ & 30 & $17.5-50$ & 25 & $\begin{array}{l}18.8- \\
30.4\end{array}$ & 30 & $17-47.5$ & 50 & $27.5-60$ & 0.1 \\
\hline $\begin{array}{l}\text { Maximum capacity for lower gastrointesti- } \\
\text { nal procedures per week per facility }\end{array}$ & 10 & $7.5-20$ & 9.5 & $5-16.2$ & 10 & $8.5-20$ & 15 & $8-20$ & 0.5 \\
\hline $\begin{array}{l}\text { Patient cost for diagnostic endoscopy } \\
\text { (USD) }\end{array}$ & 100 & $53-150$ & 100 & $90-133$ & 117 & $70-180$ & 12 & $8.5-59.6$ & $<0.001$ \\
\hline $\begin{array}{l}\text { Patient cost for therapeutic endoscopy } \\
\text { (USD) }\end{array}$ & 203 & $\begin{array}{l}150- \\
312\end{array}$ & 225 & $175-288$ & 250 & $\begin{array}{l}200- \\
350\end{array}$ & 34 & $6.63-119$ & $<0.001$ \\
\hline $\begin{array}{l}\text { IQR, interquartile range; USD, United States } \\
(9,45,17) \text {, maximum upper gastrointestinal ca } \\
(7,31,10) \text {. } \\
\text { Missing values for mission, private, public: fac } \\
\text { scopes }(0,20,0) \text {; maximum upper gastrointest } \\
1 P \text { values compare facility type results using a } \\
{ }^{2} \text { Primary = first level hospital, secondary = sec } \\
{ }^{3} \text { Outpatient/primary vs. secondary/tertiary. } \\
{ }^{4} \text { No vs any yes. }\end{array}$ & $\begin{array}{l}\text { lars. Denor } \\
\text { acity }(8,43 \\
\text { ty level }(0, \\
\text { al }(1,22,0) \\
\text { ischer's ex } \\
\text { ind level ho }\end{array}$ & $\begin{array}{l}\text { inator value } \\
\text { 7), maximu } \\
\text {,1); days p } \\
\text { naximum Ic } \\
\text { t test for pr } \\
\text { ital, tertiar }\end{array}$ & $\begin{array}{l}\text { for contin } \\
\text { n lower gas } \\
\text { week }(1,2 \\
\text { wer gastroi } \\
\text { pportions a } \\
=\text { third lev }\end{array}$ & $\begin{array}{l}\text { us variables } \\
\text { rointestinal c } \\
\text { 0); emergen } \\
\text { estinal }(1,23 \\
\text { a Kruskal-W } \\
\text { hospital. }\end{array}$ & $\begin{array}{l}\text { Mission, Pri } \\
\text { pacity }(8,42 \\
\text { y }(0,20,0) ; f \\
\text { ); cost diag } \\
\text { Ilis rank sur }\end{array}$ & $\begin{array}{l}\text { te, Public): } \\
\text { 17), cost dia } \\
\text { Joroscopy (0 } \\
\text { ostic (2,24, } \\
\text { test for com }\end{array}$ & $\begin{array}{l}\text { lastroscope } \\
\text { gnostic (7,4 } \\
\text {,20,0); gast } \\
\text { ); cost ther } \\
\text { parison of }\end{array}$ & $\begin{array}{l}(9,45,17) \text {, co } \\
, 11) \text {, cost the } \\
\text { oscopes }(0,20 \\
\text { peutic }(2,34,7 \\
\text { ntinuous vari }\end{array}$ & $\begin{array}{l}\text { noscopes } \\
\text { peutic } \\
\text { ); colono- } \\
\text { les. }\end{array}$ \\
\hline
\end{tabular}




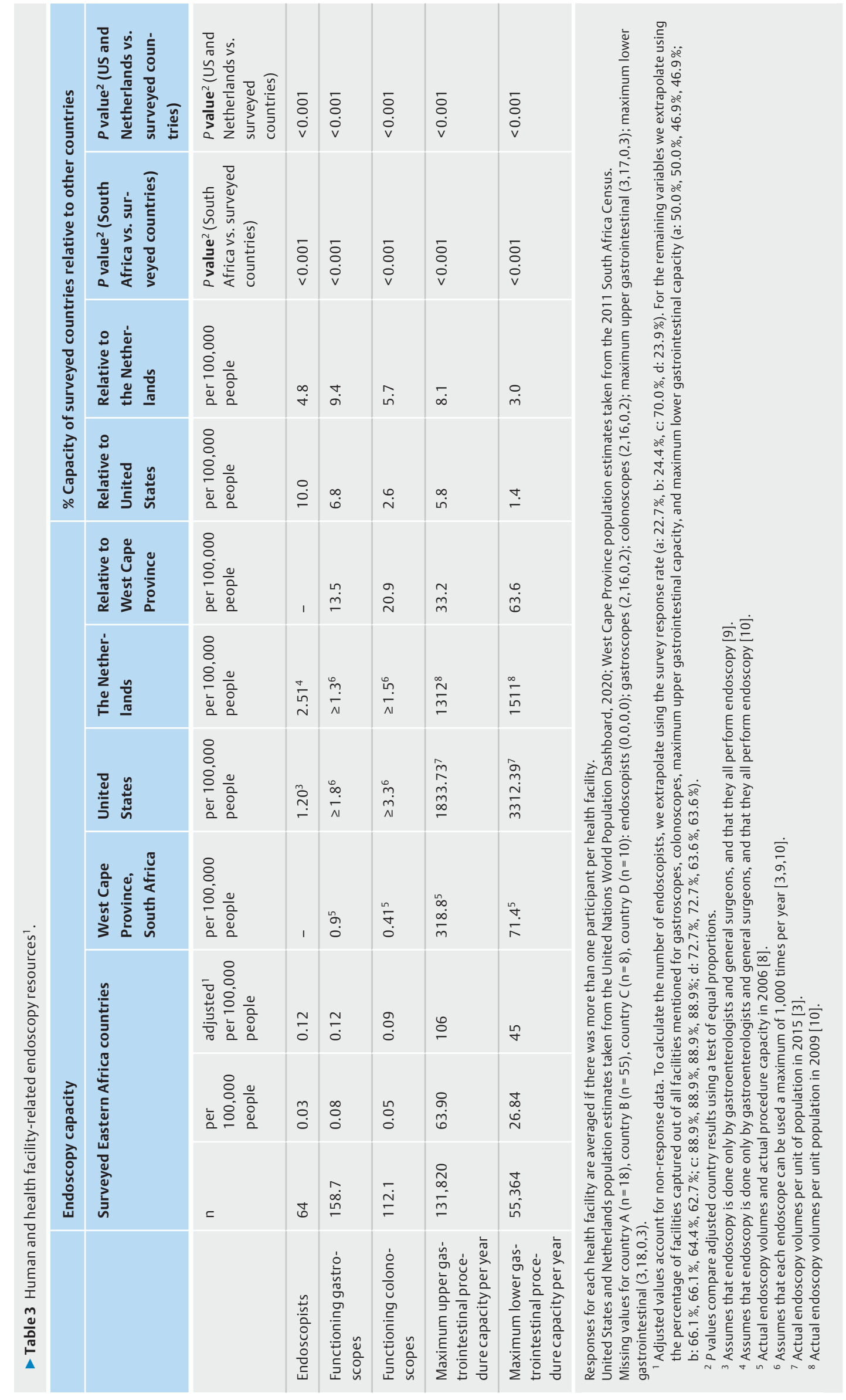


- Table 4 Barriers to provision of endoscopy services by place of employment.

\begin{tabular}{|c|c|c|c|c|c|c|c|c|c|}
\hline & \multicolumn{2}{|c|}{ Private sector } & \multicolumn{2}{|c|}{ Public sector } & \multicolumn{2}{|c|}{ Both } & \multicolumn{2}{|c|}{ Total } & \multirow[t]{2}{*}{$P$ value } \\
\hline & n & $\%$ & $\mathbf{n}$ & $\%$ & $\mathbf{n}$ & $\%$ & $\mathbf{n}$ & $\%$ & \\
\hline Number of respondents & 2 & 9.1 & 19 & 47.5 & 10 & 47.6 & 31 & 37.3 & \\
\hline \multicolumn{10}{|l|}{ Endoscopy equipment } \\
\hline - Lack of functioning equipment & 11 & 50.0 & 30 & 75.0 & 18 & 85.7 & 63 & 75.9 & 0.5 \\
\hline - Lack of disinfection supplies & 6 & 27.3 & 6 & 15.0 & 5 & 23.8 & 20 & 24.1 & 0.6 \\
\hline - Availability of accessories & 7 & 31.8 & 15 & 37.5 & 12 & 57.1 & 37 & 44.6 & 0.6 \\
\hline - Overall (yes to any of the above) & 14 & 63.6 & 34 & 85.0 & 19 & 90.5 & 67 & 80.7 & 0.7 \\
\hline \multicolumn{10}{|l|}{ Facility limitations } \\
\hline - Time constraints & 6 & 27.3 & 2 & 5.0 & 7 & 33.3 & 17 & 20.5 & 0.03 \\
\hline - Space constraints & 0 & 0.0 & 5 & 12.5 & 1 & 4.8 & 6 & 7.2 & 0.3 \\
\hline - Unpredictable electricity & 1 & 4.5 & 7 & 17.5 & 1 & 4.8 & 10 & 12.0 & 0.3 \\
\hline - Lack of pathology services & 4 & 18.2 & 9 & 22.5 & 3 & 14.3 & 16 & 19.3 & 0.9 \\
\hline - Overall (yes to any of the above) & 8 & 36.4 & 15 & 37.5 & 8 & 38.1 & 31 & 37.3 & 1.0 \\
\hline \multicolumn{10}{|l|}{ Personnel } \\
\hline - Lack of trained endoscopists & 12 & 54.5 & 23 & 57.5 & 15 & 71.4 & 53 & 63.9 & 0.9 \\
\hline - Lack of support staff & 11 & 50.0 & 17 & 42.5 & 10 & 47.6 & 40 & 48.2 & 0.9 \\
\hline - Overall (yes to any of the above) & 13 & 59.1 & 27 & 67.5 & 15 & 71.4 & 55 & 66.3 & 0.9 \\
\hline \multicolumn{10}{|l|}{ Cost } \\
\hline $\begin{array}{l}\text { - Lack of insurance coverage for } \\
\text { endoscopy services }\end{array}$ & 11 & 50.0 & 15 & 37.5 & 14 & 66.7 & 40 & 48.2 & 0.4 \\
\hline $\begin{array}{l}\text { - Initial cost of purchasing endoscopy } \\
\text { equipment }\end{array}$ & 12 & 54.5 & 19 & 47.5 & 16 & 76.2 & 48 & 57.8 & 0.5 \\
\hline $\begin{array}{l}\text { - Cost of maintaining endoscopy } \\
\text { equipment }\end{array}$ & 13 & 59.1 & 22 & 55.0 & 16 & 76.2 & 54 & 65.1 & 0.8 \\
\hline $\begin{array}{l}\text { - Patients are unable to pay endoscopy } \\
\text { fees }\end{array}$ & 11 & 50.0 & 9 & 22.5 & 9 & 42.9 & 29 & 34.9 & 0.3 \\
\hline - Overall (yes to any of the above) & 18 & 81.8 & 29 & 72.5 & 20 & 95.2 & 67 & 80.7 & 0.8 \\
\hline \multicolumn{10}{|l|}{ Regulatory } \\
\hline $\begin{array}{l}\text { - Obtaining governmental approval to } \\
\text { offer endoscopy services }\end{array}$ & 2 & 9.1 & 5 & 12.5 & 1 & 4.8 & 8 & 9.6 & 0.9 \\
\hline $\begin{array}{l}\text { - Governmental purchase of endos- } \\
\text { copy equipment for facility }\end{array}$ & 0 & 0.0 & 15 & 37.5 & 10 & 47.6 & 26 & 31.3 & 0.01 \\
\hline - Overall (yes to any of the above) & 2 & 9.1 & 19 & 47.5 & 10 & 47.6 & 31 & 37.3 & 0.1 \\
\hline
\end{tabular}

not have ready access to endoscope repair services and must send damaged endoscopes to another continent for repair, attempt the repair themselves, or remove the endoscope permanently from service and attempt to obtain another endoscope. Many African endoscopists have had the experience of sending their endoscope far away for repair, only to receive an invoice that they cannot afford to pay and hence never receiving their endoscope back. Paradoxically, the difficulty of obtaining endo- scope repair increases the overall costs of endoscopy services by shortening the usable lifespan of endoscopes.

The challenges we identified are opportunities for innovation. There is a large potential market for solutions that meet the needs of limited-resource contexts. Endoscopic systems with lower initial and per-procedure costs, and disposable or semi-disposable endoscopes with no need for repair could dramatically increase endoscopic capacity in countries such as those we studied. In addition, there is an opportunity to 
- Table 5 How facilities obtain and repair endoscopes.

\begin{tabular}{|c|c|c|c|c|c|c|c|c|c|c|c|}
\hline & \multicolumn{2}{|c|}{ Country A } & \multicolumn{2}{|c|}{ Country B } & \multicolumn{2}{|c|}{ Country C } & \multicolumn{2}{|c|}{ Country D } & \multicolumn{2}{|c|}{ Total } & \multirow[t]{2}{*}{$P$ value $^{1}$} \\
\hline & $\mathbf{n}$ & $\%$ & $\mathbf{n}$ & $\%$ & $\mathbf{n}$ & $\%$ & $\mathbf{n}$ & $\%$ & $\mathbf{n}$ & $\%$ & \\
\hline How are endoscopes obtained? & 14 & - & 40 & - & 7 & - & 16 & - & 77 & - & \\
\hline - Donation (used and new) & 7 & 50.0 & 10 & 25.0 & 7 & 100.0 & 11 & 68.8 & 35 & 45.5 & $<0.001$ \\
\hline $\begin{array}{l}\text { - Purchase by facility (used and } \\
\text { new) }\end{array}$ & 12 & 85.7 & 36 & 90.0 & 0 & 0.0 & 1 & 6.3 & 49 & 63.6 & $<0.001$ \\
\hline - Purchase by government & 3 & 21.4 & 7 & 17.5 & 0 & 0.0 & 0 & 0.0 & 10 & 13.0 & 0.2 \\
\hline - Research funding & 0 & 0.0 & 2 & 5.0 & 0 & 0.0 & 10 & 62.5 & 12 & 15.6 & $<0.001$ \\
\hline How are endoscopes repaired? & 13 & - & 38 & - & 7 & - & 15 & - & 73 & - & \\
\hline - Unable to repair & 4 & 30.8 & 6 & 15.8 & 2 & 28.6 & 4 & 26.7 & 16 & 21.9 & 0.5 \\
\hline - Self-repair & 0 & 0.0 & 7 & 18.4 & 1 & 14.3 & 2 & 13.3 & 10 & 13.7 & 0.4 \\
\hline - Sent for repair in-country & 4 & 30.8 & 27 & 71.1 & 0 & 0.0 & 1 & 6.7 & 32 & 43.8 & $<0.001$ \\
\hline - Sent elsewhere in Africa & 1 & 7.7 & 6 & 15.8 & 0 & 0.0 & 9 & 60.0 & 16 & 21.9 & 0.002 \\
\hline - Sent elsewhere in the world & 6 & 46.2 & 14 & 36.8 & 5 & 71.4 & 10 & 66.7 & 35 & 47.9 & 0.1 \\
\hline Who pays for endoscope repair? & 12 & - & 40 & - & - & & 14 & - & 66 & - & \\
\hline - Donor & 2 & 16.7 & 4 & 10.0 & - & - & 2 & 14.3 & 8 & 12.1 & 0.7 \\
\hline - Endoscopist & 0 & 0.0 & 7 & 17.5 & - & - & 2 & 14.3 & 9 & 13.6 & 0.4 \\
\hline - Facility & 10 & 83.3 & 31 & 77.5 & - & - & 4 & 28.6 & 45 & 68.2 & 0.002 \\
\hline - Government & 1 & 8.3 & 4 & 10.0 & - & - & 1 & 7.1 & 6 & 9.1 & 1.0 \\
\hline - Research funds & 0 & 0.0 & 1 & 2.5 & - & - & 11 & 78.6 & 12 & 18.2 & $<0.001$ \\
\hline
\end{tabular}

strengthen local capacity for repair of endoscopes. Additional endoscopy training programs are likely to develop in response to increased access to endoscopy technology. In the sub-Saharan Africa context we think that every general surgeon and gastroenterologist should be able to perform endoscopy, and that non-specialist and non-physician endoscopists could be instrumental in expanding endoscopy capacity [18].

Governments, research institutions, development agencies and industry partners all have key roles to play in promoting growth and innovation in endoscopy, and we believe that existing partnerships have been pivotal in achieving what has already been accomplished. Our analysis of functioning endoscopy services throughout the surveyed countries suggests that endoscopy is feasible and sustainable in eastern Africa. We know that training is flourishing in some of the locations we studied, through ongoing efforts to incorporate endoscopy in residency and fellowship curricula [19], nevertheless, large increases in capacity are still needed. National surgical and gastroenterology societies can champion training of endoscopists and engage with governments to chart pathways to sustainable provision of endoscopy services. In addition, collaboration and teaching can be enhanced and maintained via remote teaching and virtual learning platforms. Given the proportion of endoscopy services provided by private institutions, there may be an opportunity to utilize these facilities for training in endoscopy
[20]. Potential solutions to these training needs will have to be tailored to each country's unique resources and needs to help train and retain the specialist workforce. [21] Other potential solutions include training of nurse endoscopists (NEs). This concept has been described on the continent. However, it has not had widespread acceptance as has been the case in the United Kingdom and other parts of Europe [22].

Our study has limitations, and our results are based on several assumptions. Our survey response rate was low, and we mitigated this limitation by extrapolating results to all non-respondents. In addition, we could have missed healthcare facilities that offer endoscopy services; however, we mitigated this limitation by asking respondents to list other healthcare facilities throughout their country that might offer endoscopy, and we adjusted our results to include all reported facilities for which we did not have data. Our survey did not include information on support personnel like nurse endoscopists, and this is an opportunity for future research. There were some responses from nurses but these were mainly on the provision of endoscopic services. Our extrapolation of study results to nonrespondents and additional facilities likely led us to overestimate endoscopy capacity: anecdotal interactions suggest that survey recipients who do not perform endoscopy were unlikely to complete the survey, and we know that most of the facilities for which we do not have data are small private clinics staffed 
by one endoscopist. In addition, we assumed that endoscopy is performed only by members of national gastroenterology and surgical societies, but it is certainly possible that others are performing endoscopy, with or without formal training, and this may have led us to underestimate endoscopy capacity. However, from our knowledge of local and national medical practice we believe there are few such endoscopists in the countries we studied, and that they are not working in major population centers or larger healthcare facilities. Furthermore, we made the same assumption when drawing comparisons to the United States and the Netherlands, and omitted Dutch non-specialists who perform endoscopy from our calculations [10]. Finally, we could only find recent national endoscopy procedure volumes and potential endoscopist numbers for two resource-rich countries and would have preferred to include more comparative data. Even for these two countries we could find no estimate of the number of functioning endoscopes in use. We chose to calculate a lower limit for this number by assuming that one endoscope is at most used for 1,000 procedures a year (or four procedures per day, 5 days a week for 50 weeks a year) in the United States and the Netherlands. We suspect that the number of functioning endoscopes in resource-rich countries is much higher, again leading to an overly optimistic estimate of endoscopy capacity in eastern Africa.

Endoscopy capacity is severely limited in eastern Africa, despite a high burden of gastrointestional disease. Expanded capacity requires additional endoscopists and endoscopes. These, in turn, require innovations that improve the cost structure and sustainability of endoscopic services and provide more opportunities for endoscopy training.

\section{Competing interests}

Dr. Mwachiro is a consultant for Boston Scientific.

\section{References}

[1] Hassan C, Aabakken L, Ebigbo A et al. Partnership with African Countries: European Society of Gastrointestinal Endoscopy (ESGE) - Position Statement. Endosc Int Open 2018; 6: E1247-E1255

[2] Van Loon K, Mwachiro MM, Abnet CC et al. The African Esophageal Cancer Consortium: A Call to Action. J Glob Oncol 2018; 4: 1-9

[3] Peery AF, Crockett SD, Murphy CC et al. Burden and cost of gastrointestinal, liver, and pancreatic diseases in the united states: update 2018. Gastroenterology 2019; 156: 254-272

[4] Kayamba V, Sinkala E, Mwanamakondo $S$ et al. Trends in upper gastrointestinal diagnosis over four decades in Lusaka, Zambia: a retrospective analysis of endoscopic findings. BMC Gastroenterol 2015; 15: 127

[5] Ayuo PO, Some FF, Kiplagat J. Upper gastrointestinal endoscopy findings in patients referred with upper gastrointestinal symptoms in El- doret, Kenya: a retrospective review. East Afr Med J 2014; 91: 267273

[6] Agyei-Nkansah A, Duah A, Alfonso M. Indications and findings of upper gastrointestinal endoscopy in patients presenting to a District Hospital, Ghana. Pan Afr Med J 2019; 34: 82

[7] Kamdem J, Palmer D, Barrier C et al. Diagnostic yield of gastrointestinal endoscopy in North West Region Cameroon and trends in diagnosis over time. Pan Afr Med J 2018; 29: 178

[8] Watermeyer G, Van Wyk ME, Goldberg BA. Audit of provincial gastroenterology services in the Western Cape. S Afr J Surg 2008; 46: 68-72

[9] American Association of Medical Colleges. Number of people per active physician by specialty, 2017. https://www.aamc.org/data-reports/workforce/interactive-data/number-people-active-physicianspecialty-2017 accessed January 2021

[10] van Turenhout ST, Terhaar sive Droste JS et al. Anticipating implementation of colorectal cancer screening in The Netherlands: a nationwide survey on endoscopic supply and demand. BMC Cancer 2012; 12: 46

[11] Perl D, Leddin D, Bizos D et al. Endoscopic capacity in West Africa. Afr Health Sci 2016; 16: 329-338

[12] Institute for Health Metrics and Evaluation (IHME). Findings from the Global Burden of Disease Study 2017. Seattle: WA: IHME; 2018

[13] Akinyemiju T, Abera S. Global Burden of Disease Liver Cancer Collaboration. et al. The burden of primary liver cancer and underlying etiologies from 1990 to 2015 at the global, regional, and national level: results from the global burden of disease study 2015. JAMA Oncol 2017; 3: 1683-1691

[14] Malekzadeh F, Sepanlou SG, Poustchi H et al. Burden of gastrointestinal and liver diseases in iran: estimates based on the global burden of disease, injuries, and risk factors study, 2010. Middle East J Dig Dis 2015; 7: 138-154

[15] Fitzmaurice C, Allen C. Global Burden of Disease Cancer Collaboration. et al. Global, regional, and national cancer incidence, mortality, years of life lost, years lived with disability, and disability-adjusted life-years for 32 cancer groups, 1990 to 2015: a systematic analysis for the global burden of disease study [published correction appears in JAMA Oncol. JAMA Oncol 2017; 3: 524-548

[16] Census 2011: Census in brief. Pretoria: Statistics South Africa. 2012

[17] Loots E, Clarke DL, Newton K et al. Endoscopy services in KwaZuluNatal Province, South Africa, are insufficient for the burden of disease: Is patient care compromised? S Afr Med J 2017; 107: 10221025

[18] Wilhelm T], Mothes H, Chiwewe D et al. Gastrointestinal endoscopy in a low budget context: delegating EGD to non-physician clinicians in Malawi can be feasible and safe. Endoscopy 2012; 44: 174-176

[19] Parker RK, Mwachiro MM, Topazian HM et al. Gastrointestinal endoscopy experience of surgical trainees throughout rural Africa. Surg Endosc 2020: doi:10.1007/s00464-020-08174

[20] Mulder CJ], Puri AS, Reddy DN. Gastroenterology training in private hospitals: India vs S Africa. S Afr Gastroenterol Rev 2010; 16: 948-952

[21] Modcoicar P, Mondlane L, Dimande L et al. Gastroenterology in Mozambique - A pathway for development. S Afr Gastroenterol Rev 2017; 15: 19-21

[22] Mulder CJ], Fisher E, Klemt-Kropp M et al. Nurse Endoscopists in South Africa 2020-2025. S Afr Gastroenterol Rev 2019; 17: 9-12 